\title{
Medical Undergraduate Students' Perception about Online Education during the COVID-19 Pandemic
}

\author{
Hatem Allam ${ }^{1,2 *}$ D , Nouf K. Alghamdi ${ }^{2}$, Sarah A. Alghamdi ${ }^{2}$, Arwa A. Alzaedi ${ }^{2}$, Haya A. Alharthi ${ }^{2}$, Rawan R. Al sufyani ${ }^{2}$, \\ Shahd T. Al osaimi ${ }^{2}$, Lamiaa K. Elsayyad ${ }^{3}$ \\ ${ }^{1}$ Department of Physical Therapy, Misr University for Sciences and Technology, Egypt; ${ }^{2}$ Department of Physical Therapy, \\ College of Applied Medical Sciences, Taif University, Ta'if, Saudi Arabia; ${ }^{3}$ Department of Biomechanics, Faculty of Physical \\ Therapy, Cairo University, Giza, Egypt
}

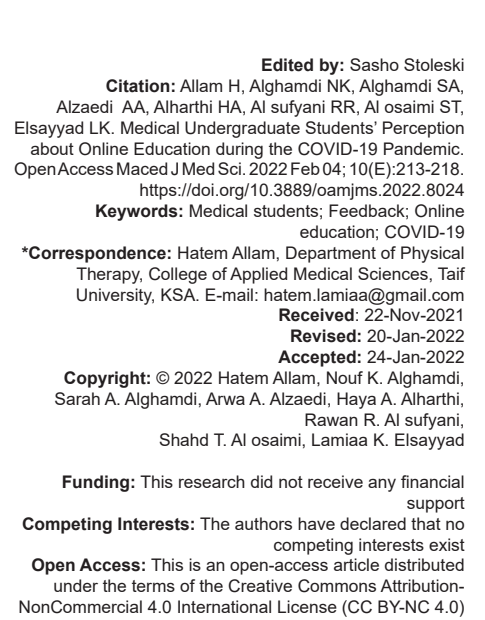

\section{Abstract}

BACKGROUND: The influence of the COVID-19 pandemic is great not only on general health but also on regular learning worldwide.

AIM: This study analyzed medical undergraduate students' feedback about online education at Taif University during the COVID-19 pandemic.

METHODS: Five hundred undergraduate medical students from the four medical colleges at Taif University participated in the current study. They were requested to give their feedback about online medical education through an online questionnaire. The questionnaire was prepared and administered to the medical students at different academic levels through Google forms. The current study is a cross-sectional study.

RESULTS: The respondents who can ask questions during e-classes were significantly higher than those who had not this opportunity. A significantly higher number of students reported that the shared material was useful. In addition, the study results indicated significantly poor student-teacher interaction during the e-classes. Finally, about 231 of the respondents (46.2\%) preferred physical classes over e-classes and 140 of respondents $(28 \%)$ preferred online classes over physical classes, and the remaining number, $129(25.8 \%)$, mentioned that online and conventional education are both the same.

CONCLUSION: Most students said that conventional education is better than online education. The combination of online and formal education can be implemented after the COVID-19 pandemic to satisfy all parties.

\section{Introduction}

At this time, the world is dealing with a pandemic of an infectious respiratory syndrome caused by a new coronavirus named COVID-19 [1]. By 12 February 2020, there were 43,103 confirmed cases of COVID-19. Most of these cases were from China [2]. The influence of the COVID-19 pandemic is great not only on general health but also on regular learning worldwide. These negative influences are due to preventive measures being taken to decrease its spread. The social distancing (i.e., widening the space between individuals) during the COVID-19 pandemic has pushed educational institutes to empty their classrooms and take the students away. Hence, conventional face-to-face education has been shifted to online teaching [3].

Medical education is also disturbed due to the cancellation of conventional face-to-face education [4]. As there is doubt about the length of this pandemic and the needed preventive measures, the education of future doctors requires strong and quick consideration [5]. Rajab et al. [6] mentioned numerous challenges to online medical education during the COVID-19 pandemic. Examples of these challenges are student evaluation, technology usage, academic stress associated with the pandemic, and time management.

In Saudi Arabia, about 1 million students at universities all over the country were highly influenced when all universities were closed, and teaching was converted from face-to-face education classes to online education from home through the Blackboard learning management system (BLS) [7]. BLS is a system for the educational process management and students' follow-up. It has certain advantages, such as it controls the efficiency of the educational process in the educational institution. It provides great opportunities for students to communicate with their courses outside the lecture hall anywhere and at any time through various tools. In addition, it allows communication with the course professor and the rest of the students enrolled in the same course by various electronic means. Faculty 
members can manage all courses online, and faculty can post documents, make ads, send e-mail, and create assessments online through the BLS. Course materials are available $24 \mathrm{~h}$ a day, 7 days a week, from anywhere, allowing students to learn when and where they want to [8]. Most institutions, including Taif University, have shifted to distance learning in the easiest and most suitable ways, including blackboard.

As this was one of the essential options for medical students to continue their learning, it will be important to assess the medical students' feedback on online learning. Consequently, this study improves our understanding of the medical students' perceptions of using online classes. In addition, exploring their feedback will allow the educational institutes to take future decisions regarding the application of online learning approaches. These future decisions will help educational institutes to train staff and students and develop strategies to overcome difficulties and obstacles. Therefore, this study aimed to assess medical undergraduate students' feedback about online learning at Taif University during the COVID-19 pandemic.

\section{Materials and Methods}

Five hundred undergraduate medical students from the four medical colleges at Taif University participated in the current study. They were requested to give their feedback about online medical education through an online questionnaire. The online survey is an effective way to get notarized data from online people, and at the same time, it is a good method to decrease the cost when implementing a study [9]. The medical colleges were the College of Applied Medical Sciences, College of Medicine, College of Dentistry and College of Pharmacy, Taif University, Taif, KSA. Data were gathered over 1 month, from February to March 2021. Each participant signed an electronic consent form before filling the questionnaire. The used questionnaire was prepared and administered to the medical students at different academic levels through Google forms. The declaration about the questionnaire was made through the BLS with the help of university professors and colleagues.

The used questionnaire takes about $3 \mathrm{~min}$ to be completed. It contained an introductory paragraph that informs all participants about the study's main objective and the anonymity and confidentiality of the data. In addition, they have the right not to answer any questions or withdraw from the study without consequences. Data was collected using spreadsheets. The used questionnaire is valid. A group of faculty members validated it at the India institute of medical sciences, Jodhpur, Rajasthan, and India. The questionnaire consists of four categories. The first category is the characteristics of the study respondents containing sex, college, department, and academic level. The second category is the feedback question which gives three responses (previously attended any online classes? if the student was allowed to ask questions during the e-classes? and if the material shared before/after e-classes was useful). The answer is by "yes" or "no." The third category is how the students rate their interaction with the teacher during e-classes. This contains three responses (as good as the physical classroom, better than the physical classroom, or poorer than the physical classroom). The last category evaluates their general opinion about e-classes. The participant selects one of three responses (physical classes are better than e-classes, e-classes are as good as physical classes, or e-classes are better than physical classes).

\section{Statistical analysis}

The current study is a cross-sectional study. Descriptive statistics (percentage) described medical undergraduate students' feedback about online education at Taif University. Additionally, SPSS version 26 was used to conduct chi-square analysis at an alpha level of significance of 0.05 to compare the responses to each question with each other.

\section{Results}

\section{Descriptive analysis of respondents' characteristics and responses}

A total of 500 undergraduate medical students from all academic levels responded to the survey. The participants represented the different medical colleges at Taif University. About 230 (46\%) participants were males, and 270 (54\%) were female students. The details of participants' characteristics are shown in Table 1. Table 2 describes the number and percentage for each response regarding the feedback questions.

Table 1: Characteristics of the study respondents $(n=500)$

\begin{tabular}{lll}
\hline Characteristics & No & Percentage (\%) \\
\hline Gender & & \\
Males & 230 & 46 \\
Females & 270 & 54 \\
$\quad$ Total & 500 & 100 \\
Academic year & & \\
$1^{\text {st }}$ year & 56 & 11.2 \\
$2^{\text {nd }}$ year & 52 & 10.4 \\
$3^{\text {td }}$ year & 105 & 21 \\
$4^{\text {th }}$ year & 229 & 45.8 \\
$5^{\text {th }}$ year & 30 & 6 \\
$6^{\text {th }}$ year & 28 & 5.6 \\
Total & 500 & 100 \\
College & & \\
College of applied medical sciences & 211 & 42.2 \\
College of medicine & 117 & 23.4 \\
College of pharmacy & 94 & 18.8 \\
College of dentistry & 78 & 15.6 \\
Total & 500 & 100 \\
\hline
\end{tabular}




\section{Chi-square test for students' responses}

Thenumberofstudents whoattendede-classes before the COVID-19 pandemic was significantly higher than those who did not. Respondents who reported that they had an opportunity to ask questions during e-classes were significantly higher than those who had not had this opportunity. Regarding the shared material usefulness, a significantly higher number of students reported that the shared material was useful. The number of the students who reported poor interaction with the teacher during the e classes was significantly higher than those who reported good or fair interaction. Finally, a substantially higher number of students preferred physical classes over e-classes (Table 3 and Figure 1).

\section{Discussion}

The study's main aim was to analyze the medical undergraduate students' feedback about online education at Taif University during the COVID-19 pandemic. We selected the medical students to participate in this timely study because a recent study has shown that medical students are more willing to be part of the decision-making process concerning matters that may affect their education and ensure that their opinions are taken into consideration [10]. Thus, it was wise to engage medical students in renovating education at this difficult time. Moreover, the response rate of medical students to this survey is considered high

Table 2: The detailed responses of the participants

\begin{tabular}{|c|c|c|c|}
\hline Feedback question & Response & No & $\begin{array}{l}\text { Percentage } \\
(\%)\end{array}$ \\
\hline Previously attended any online & Yes & 376 & 75.2 \\
\hline classes? & No & 124 & 24.8 \\
\hline Given the opportunity to ask & Yes & 347 & 69.4 \\
\hline questions during online classes & No & 153 & 30.6 \\
\hline The material shared before/after & Yes & 355 & 71 \\
\hline e-classes was useful? & No & 145 & 29 \\
\hline How do you rate your interaction & As good as physical classroom & 145 & 29 \\
\hline with the teacher during online & Better than a physical classroom & 145 & 29 \\
\hline classes? & Poorer than a physical classroom & 210 & 42 \\
\hline \multirow[t]{3}{*}{$\begin{array}{l}\text { Select the statement that applies } \\
\text { best to you? }\end{array}$} & $\begin{array}{l}\text { Physical classes are better than } \\
\text { online classes. }\end{array}$ & 231 & 46.2 \\
\hline & $\begin{array}{l}\text { Online classes are as good as } \\
\text { physical classes. }\end{array}$ & 129 & 25.8 \\
\hline & $\begin{array}{l}\text { Online classes are better than } \\
\text { physical classes }\end{array}$ & 140 & 28 \\
\hline
\end{tabular}

because the medical students became well adapted to the new ways of learning. At the same time, the stress level became lower. In addition, these students quickly realized that accurate feedback is critical when shifting to a novel education mood during a healthcare emergency, which elevated the response rate.

Regarding the interaction between the students and teachers, the current study results revealed that most students stated that the interaction between them and teachers during online classes was poorer than in physical classes. Fichten et al. [11] supported these findings when they reported that there was a lack of interaction, active participation, and discussions between the students and lecturers in online learning. This may be attributed to certain technical issues as poor internet, lack of experience with online education, and stresses and anxiety related to the pandemic [12]. In addition, Ragab et al. [6] reported that several challenges influenced online education and, consequently, studentteacher interaction. Examples of these challenges are communication, usage of technology, and academic stress associated with the pandemic. They added that overcoming these challenges may help improve interaction and communication between students and teachers during online classes and may also enhance communication in conventional physical classes.

Concerning the students' preference for physical education over online education, 231 respondents $(46.2 \%)$ mentioned that they prefer physical classes over online classes. These findings are supported by Singh et al. [13] when they evaluated the medical students' perspectives about online education at the India institute of medical sciences, Jodhpur, Rajasthan, India. They reported that most students still believed that conventional physical classrooms were better than online classrooms. This may be related to the better interaction between students and their teachers at physical classes than online classes. Furthermore, the respondents' preference for physical classes may be related to that the medical institutes have postponed the practical parts to the summer. These adjustments may lead to a decrease in the satisfaction level of medical students with online education. Tokuç and Varol [14] supported this finding when they conducted a study about medical education in Turkey during COVID-19. They found that all medical institutes converted the theoretical contents of the curricula to an

Table 3: Chi-square analysis for students' responses

\begin{tabular}{|c|c|c|c|c|c|c|c|}
\hline Questionnaire items & Response & Observed $\mathrm{N}$ & Expected $\mathrm{N}$ & Residual & Chi-square & $\mathrm{df}$ & Sig. \\
\hline \multirow[t]{2}{*}{ Previously attended any online classes. } & Yes & 376 & 250.0 & 126.0 & $127.008^{\mathrm{a}}$ & 1 & 0.000 \\
\hline & No & 124 & 250.0 & -126.0 & & & \\
\hline \multirow[t]{2}{*}{ Given the opportunity to ask questions during the e-classes? } & Yes & 347 & 250.0 & 97.0 & $75.272^{\mathrm{a}}$ & 1 & 0.000 \\
\hline & No & 153 & 250.0 & -97.0 & & & \\
\hline \multirow[t]{2}{*}{ The material shared before/after e-classes was useful. } & Yes & 355 & 250.0 & 105.0 & $88.200^{\mathrm{a}}$ & 1 & 0.000 \\
\hline & No & 145 & 250.0 & -105.0 & & & \\
\hline \multirow[t]{3}{*}{ How do you rate your interaction with the teacher during e-classes? } & Better & 145 & 166.7 & -21.7 & $16.900^{\mathrm{b}}$ & 2 & 0.000 \\
\hline & As good as & 145 & 166.7 & -21.7 & & & \\
\hline & Poorer & 210 & 166.7 & 43.3 & & & \\
\hline \multirow[t]{3}{*}{ Select the statement that applies best to you: } & E-classes better & 140 & 166.7 & -26.7 & $37.612^{\mathrm{b}}$ & 2 & 0.000 \\
\hline & As good as & 129 & 166.7 & -37.7 & & & \\
\hline & Physical classes better & 231 & 166.7 & 64.3 & & & \\
\hline
\end{tabular}




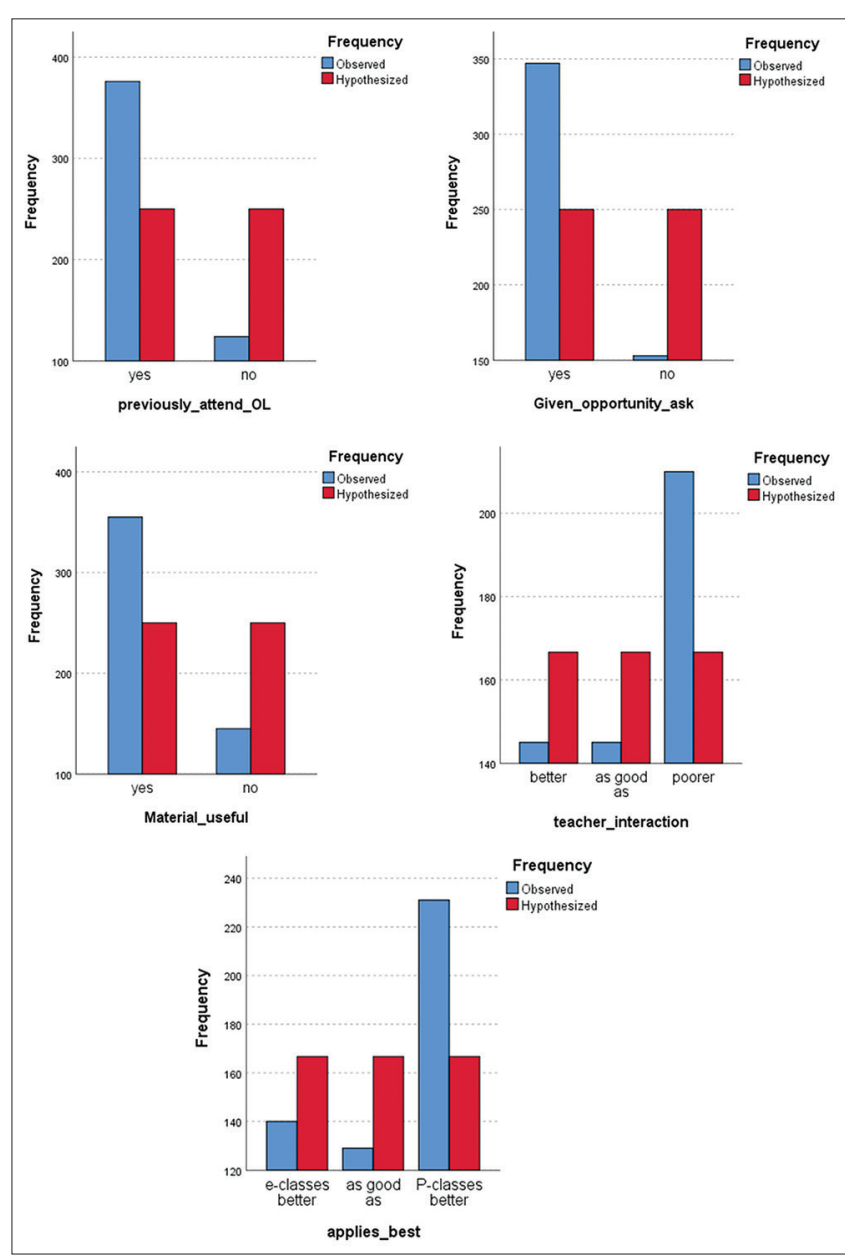

Figure 1: Chi-square analysis for students' responses

online strategy. Practical parts and examinations were delayed to the summer term, increasing the medical students' stress level.

Moreover, Moawad [7] studied university students' academic stress due to online learning during the COVID19 pandemic. He stated that certain stresses negatively affected university students when they were engaged in online education. For example, doubt about the end of semester exams and assessments, quality of the internet, and insufficient time to complete the tasks required from the students. All these factors made many students prefer physical classes over online classes. Furthermore, Verma et al. [15] added that the deficiencies found in the practical and clinical aspects of the courses may have reinforced students' preference for conventional classes over distance education. In addition, they mentioned that conventional education is a cheap and viable method that helps to obtain knowledge, preserve routine, and improve the spirits of both teachers and students.

Concerning the preference for online classes, the study results revealed that 140 respondents (28\%) preferred online classes over physical classes. This may be attributed to the fact that all the study respondents are young adults who are clever with social media, which is considered their primary source of communication [16]. This agrees with Ragab et al. [6], who conducted a study to detect the impact of the COVID-19 pandemic on online education at the College of Medicine, Al Faisal University. They reported that many medical students mentioned that the pandemic positively impacted online education. The students were satisfied with online learning even though using educational procedures that had never been used before. They added that the experiences acquired by medical students during the first few weeks of conducting online education during the pandemic may have raised their belief in the efficiency of online medical education.

In addition, Demuyakor [17] had agreed with this category when he conducted a study to assess the satisfaction level of Ghanaian international students about online education in higher educational institutions in Beijing, China. He found that students were satisfied with the online education introduced by numerous higher educational institutions despite the few challenges identified. He justified these findings by high students' satisfaction level about the available learning resources such as explanatory videos and texts provided by teachers. Furthermore, Sun et al. [18] reported certain positive aspects of online teaching as the increase in the attendance rate of students, time, and cost-saving. Furthermore, advisors could set assignments that can be carried out at home. They added that online education turned students from passive recipients to active participants through open discussions, interactive questions and answer sessions, and presentations. Moreover, Verma et al. [15] mentioned that the student still considered these classes safe, relaxed, and interesting, which may have boosted students' preference for distance education over conventional classes.

\section{Conclusion}

Most students mentioned that conventional education is better than online education due to certain challenges. By overcoming these challenges, a combination between online education and conventional education can be implemented after the COVID-19 pandemic to satisfy all parties.

\section{Limitations of the Study}

First, we did not record the students' grade point average that may impact students' responses. Second, the questionnaire did not include items to 
justify the participants' responses. Furthermore, the study was delimited to medical students only.

\section{Recommendations}

Conducting another study to include respondents fromall other colleges other than the medical colleges. In addition, regarding the questionnaire, items to justify the participants' responses could be added, and then the validity of the questionnaire reassessed.

\section{Ethical Considerations}

The Taif University research ethics committee; approved the study. The approval number is $42-116$.

\section{Acknowledgment}

We want to thank all participants of the study who kindly spent a lot of their time and effort.

\section{Authors' Contributions}

A- Conceptualization: Hatem HAllam, and Lamiaa K. Elsayyad.

B- $\quad$ Study design: Hatem H Allam, and Lamiaa K. Elsayyad.

C- Data collection: Nouf K. ALghamdy, Sarah A. ALghamdy, Arwa A. Al zaidy, Haya A. Al harthy, Rawan R. Al sufiany, Shahd T. Al oseimy

D- Statistical analysis: Lamiaa K. Elsayyad and Hatem H Allam

E- $\quad$ Data interpretation: Nouf K. ALghamdy, Sarah A. ALghamdy, Arwa A. Al zaidy, Haya A. Al harthy, Rawan R. Al sufiany, Shahd T. Al oseimy

F- $\quad$ Literature search: Nouf K. ALghamdy, Sarah A. ALghamdy, Arwa A. Al zaidy, Haya A. Al harthy, Rawan R. Al sufiany, Shahd T. Al oseimy

G- Writing, preparing, and editing the manuscript: Hatem H Allam and Lamiaa K. Elsayyad.

$\mathrm{H}-\quad$ Obtaining the ethical approval: Nouf $\mathrm{K}$. ALghamdy, Sarah A. ALghamdy, Arwa A. Al zaidy, Haya A. Al harthy, Rawan R. Al sufiany, Shahd T. Al oseimy.

\section{References}

1. Holland M, Zaloga DJ, Friderici CS. COVID-19 Persona Protective Equipment (PPE) for the emergency physician. Visual J Emerg Med. 2020;19:100740. https://doi.org/10.1016/j. visj.2020.100740 PMid:32289084

2. Wang W, Tang J, Wei F. Updated understanding of the outbreak of 2019 novel coronavirus (2019-nCoV) in Wuhan, China. J Med Virol. 2020;92(4):441-7. https://doi.org/10.1002/jmv.25689 PMid:31994742

3. Remtulla R. The present and future applications of technology in adapting medical education amidst the COVID-19 pandemic. JMIR Med Educ. 2020;6(2):e20190. https://doi. org/10.2196/20190

PMid:32634107

4. Chick R, Clifton G, Peace K, Propper B, Hale D, Alseidi A, et al. Uso de la tecnología para mantener la educación de los residentes durante la pandemia COVID-19. Rev Educ Quirúrg. 2020;77(4):729-32.

5. Ferrel MN, Ryan JJ. The impact of COVID-19 on medical education. Cureus. 2020;12(3):e7492. https://doi.org/10.7759/ cureus.7492

PMid:32368424

6. Rajab MH, Gazal AM, Alkattan K. Challenges to online medical education during the COVID-19 pandemic. Cureus. 2020;12(7):e8966.

PMid:32766008

7. Moawad RA. Online learning during the COVID-19 pandemic and academic stress in university students. Rev Rom Pentru Educ Multid. 2020;12(1 Suppl 2):100-7.

8. Al-Qahtani AA, Higgins SE. Effects of traditional, blended and e-learning on students' achievement in higher education. J Comput Assist Learn. 2013;29(3):220-34.

9. Fricker RD. Sampling methods for online surveys. In: The SAGE Handbook of Online Research Methods. London: SAGE Puplications; 2016. p. 184-202.

10. Rajab MH, Gazal AM, Alkawi M, Kuhail K, Jabri F, Alshehri FA Eligibility of medical students to serve as principal investigator: An evidence-based approach. Cureus. 2020;12(2):e7025. https://doi.org/10.7759/cureus.7025

PMid:32117664

11. Fichten CS, Ferraro V, Asuncion JV, Chwojka C, Barile M, Nguyen MN, et al. Disabilities and e-learning problems and solutions: An exploratory study. J Educ Technol Soc. 2009;12(4):241-56.

12. Esani M. Moving from face-to-face to online teaching. Am Soc Clin Lab Sci. 2010;23(3):187-90. PMid:20734893

13. Singh K, Srivastav S, Bhardwaj A, Dixit A, Misra S. Medica education during the COVID-19 pandemic: A single institution experience. Indian Pediatr. 2020;57(7):678-9. https://doi. org/10.1007/s13312-020-1899-2

PMid:32366728

14. Tokuç B, Varol G. Medical education in Turkey in time of COVID-19. Balkan Med J. 2020;37(4):180-1. https://doi. org/10.4274/balkanmedj.galenos.2020.2020.4.003 PMid:32364692

15. Verma A, Verma S, Garg P, Godara R. Online teaching during COVID-19: Perception of medical undergraduate students. Indian J Surg. 2020;82(3):299-300.

16. Dimock M. Defining generations: Where millennials end and generation $Z$ begins. Pew Res Center. 2019;17(1):1-7. 
17. Demuyakor J. Coronavirus (COVID-19) and online learning in higher institutions of education: A survey of the perceptions of Ghanaian international students in China. Online J Commun Med Technol. 2020;10(3):e202018.
18. Sun L, Tang Y, Zuo W. Coronavirus pushes education online. Nat Mater. 2020;19(6):687. https://doi.org/10.1038/ s41563-020-0678-8

PMid:32341513 